INNOVACIÓN

\title{
Julgamento simulado do STF: Aplicação do team based learning e do project based learning no curso de Direito
}

\author{
Simulated judgment of the Supreme Federal Court: Applying the team based learning and \\ the project based learning methodology in the Law course Degree
}

\author{
Fernanda de Matos Lima Madrid \\ Universidade Estadual do Norte do Paraná, Brasil \\ Lucas Octávio Noya dos Santos \\ Universidade Estadual do Norte do Paraná, Brasil
}

\begin{abstract}
RESUMO Este artigo descreve a metodologia de Aprendizagem Baseada em Projeto (Project-Based Learning - PBL), bem como a metodologia ativa chamada de Team Based Learning (TBL) e relata sua aplicação no Curso de Direito do Centro Universitário Antônio Eufrásio de Toledo de Presidente Prudente/ SP, no Brasil, durante o $1^{\circ}$ semestre de 2017. A atividade versou sobre caso hipotético que foi criado com base em um caso real recentemente julgado pelo STF no qual se avençou a possibilidade de indenização de presos que comprovadamente vivessem em situação degradante, humilhante e vexatória dentro dos presídios. Os resultados foram divididos com os outros grupos, assim como com outros discentes e docentes da instituição no dia da sessão de julgamento simulado, que finalizou a atividade, proporcionando aos alunos experiência de entender a vertente teórica do tema e desenvolver habilidades de trabalho em equipe, pensamento crítico, oratória, bem como a habilidade para solução de problemas da vida real.
\end{abstract}

PALAVRAS-CHAVE Curso de Direito. Metodologias ativas de aprendizagem. Team Based Learning. Project-Based Learning.

ABSTRACT This article describes the methodology of Project-Based Learning (PBL), as well as the active methodology called Team Based Learning (TBL) and reports its application in the Law Course degree of the University Center Antonio Eufrásio de Presidente de Presidente Prudente / SP in Brazil during the first half of 2017. The activity deal with a hypothetical case that was created based on a real case recently judged by the Supreme Court, in which the possibility of indemnity of prisoners who were proven to live in a degrading, humiliating situation and vexatious within prisons. The 
results were divided with the other groups, as well as with other students and teachers of the institution on the day of the simulated trial session, which finalized the activity, providing students with experience of understanding the theoretical side of the subject and developing teamwork skills, critical thinking, oratory, as well as the ability to solve real-life problems.

KEYWORDS Law course. Active learning methodologies. Team Based Learning. Project-Based Learning.

\section{Introdução}

Não há como negar que metodologias ativas de aprendizagem, como Aprendizagem Baseada em Projeto (Project Based Learning - PBL) e Team Based Learning (TBL), vêm propiciando uma melhora significativa no processo de aquisição de conhecimento.

Tal fato se dá, primordialmente, pela mudança do papel do aluno na busca do conhecimento, eles se transformam nos grandes protagonistas deste processo, o que propicia um envolvimento muito superior do aluno quando comparado aos métodos de ensino convencionais. Habilidades importantes para o mercado de trabalho do século XXI podem ser desenvolvidas com a aplicação de metodologias ativas como pensamento critico, capacidade de resolução de problemas do mundo real, de autogestão, de lidar com conflitos interpessoais, trabalho em equipe, autoconfiança, condição de resolver problemas complexos, criatividade, inovação, melhora da oratória, dentre outras.

Difere-se dos sistemas tradicionais de ensino, em que o aluno tem pouca ou quase nenhuma influência em seu processo de aprendizado, as aulas são expositivas, maçantes e todo o desenvolvimento da aula já é pré-estabelecido pelo professor, impedindo que os discentes desenvolvam satisfatoriamente as referidas habilidades.

Neste diapasão, a mudança de paradigmas é necessária para que as instituições de ensino forneçam maiores oportunidades para os alunos desenvolverem atributos genéricos, além do conhecimento disciplinar.

Não é mais suficiente que o aluno obtenha seu diploma, os empregadores estão procurando mais do que apenas conhecimento e habilidades técnicas. Eles valorizam as habilidades genéricas desses individuos, assim, em nosso mercado de trabalho, $o$ que importa, não é o que sabem, mas o que podem fazer com o que conhecimento que possuem. Aqueles que têm essas habilidades terão uma vantagem efetiva no mercado de trabalho.

Nesse artigo, procurou-se relatar como a metodologia do Project Based Learning e do Team Based Learning foram empregadas pelos alunos que participam do grupo de estudos preparatório para a participação em Competição Jurídica de Julgamento Simulado da Corte Interamericana de Direitos Humanos, realizada por meio de uma parceria entre a Washington College of Law, núcleo jurídico da American University, 
e a Comissão Interamericana de Direitos Humanos, sediada em Washington DC/ USA, que apresenta como finalidade principal a promoção dos Direitos Humanos e preparação dos alunos de direito para atuarem junto ao Sistema Interamericano de Direitos Humanos (doravante SIDH), demonstrando como a Instituição de ensino Superior, por meio de dessas metodologias ativas, contribuiu para o desenvolvimento de habilidades de seus alunos, além das disciplinas teóricas, e como o resultado do referido projeto foi compartilhado com outros alunos e professores da nossa Instituição de ensino.

Buscamos expor e incentivar novas maneiras de obtenção do conhecimento, acabando com o mito de que, no Curso de Direito, a utilização de metodologias ativas é extremamente difíceis de enquadrarem tendo em conta as necessidades do curso.

A pesquisa sobre o tema e a coleta de dados foi feita pela análise de documentação indireta, vale dizer, pelo estudo doutrinário, bem como pela descrição da experiência real por nós experimentada.

O método utilizado foi o dedutivo, posto que se partiu da importância das metodologias ativas no curso de Direito (Paiva et al, 2011), analisamos as metodologias denominadas Project Based Learning e Team Based Learning, para, posteriormente, passar a narrativa da experiência vivenciada no Centro Universitário Antônio Eufrásio de Toledo de Presidente Prudente.

O trabalho está dividido da seguinte forma: metodologias ativas aplicadas no curso de Direito, breves considerações sobre Project Based Learning e Team Based Learning, o projeto e conclusão.

\section{Metodologias ativas aplicadas no curso de Direito}

Em nosso mundo moderno, em que as transformações são rápidas e repletas de complexidades, o Direito e seus operadores devem ser aptos a dar respostas inovadoras as novas necessidades, possibilitando a estabilização do convívio social. Novas formas de atuação do Direito devem ser desenvolvias a fim de enfrentar os desafios decorrentes da globalização, da mudança de paradigma tecnológico, da sustentabilidade ambiental e dos conflitos de massa.(Vieira, 2012:38)

Dentro desse contexto, as metodologias ativas (Ching, 2018; Rodríguez et al, 2016; Rodríguez, Rebolledo, 2017; Rodríguez et al, 2017; Reyes et al, 2014; Melo et al, 2017; Fernández, Aguado, 2017) se mostram de extrema importância para desenvolver nos discentes do curso de Direito habilidades que os possibilitem adotarem essa nova postura perante o seio social em que estão inseridos.

Bastos apud Neusi Aparecida Navas Berbel conceitua as Metodologias Ativas como «processos interativos de conhecimento, análise, estudos, pesquisas e decisões individuais ou coletivas, com a finalidade de encontrar soluções para um problema.» (Berbel,2017:29) 
Metodologias ativas são fundamentais para que os alunos desenvolvam habilidades de trabalho em equipe, resolução de conflitos interpessoais, pensamento críticos, bem como a habilidade para solução de problemas da vida real, com o escopo de modificar a realidade. De tal modo, a motivação do aluno passa a ser o ponto central de todo o processo de ensino-aprendizagem. Por sua vez, o professor passa a ser um facilitador desse processo de aprendizagem, assumindo o papel de tutor, e não mais de o posto de único detentor do conhecimento.

Nas palavras de Neusi Aparecida Navas Berbel (2011:29):

Podemos entender que as Metodologias Ativas baseiam-se em formas de desenvolver o processo de aprender, utilizando experiências reais ou simuladas, visando às condições de solucionar, com sucesso, desafios advindos das atividades essenciais da prática social, em diferentes contextos.

Métodos ativos de aprendizagem diferenciam-se dos sistemas tradicionais de aprendizagem, em que o aluno tem pouca influência em seu processo de aprendizado, as aulas são expositivas, tediosas e todo o desenvolvimento da aula já é pré-estabelecido pelo professor, impedindo que os discentes desenvolvam satisfatoriamente as referidas habilidades.

Procuramos apresentar e incentivar novas maneiras de obtenção do conhecimento, acabando com o mito de que no Curso de Direito a aplicação de metodologias ativas são extremamente difíceis de enquadrarem dentro das necessidades do curso.

Logo, a modificação de padrões de ensino no curso de Direito é preciso para que as instituições de ensino proporcionem maiores oportunidades para os alunos desenvolverem atributos genéricos, que não podem ser obtidos por métodos de ensino tradicionais que mantém a passividade do discente frente ao processo de aprendizagem.

\section{Breves considerações sobre project based learning e team based learning}

A metodologia denominada Project Based Learning trata-se de um modelo de ensino que possibilita que os discentes enfrentem questões do mundo real de maneira cooperativa na busca de soluções. Nas palavras de William Bender: «A ABP pode ser definida pela utilização de projetos autênticos e realistas, baseados em uma questão, tarefa ou problema altamente motivador e envolvente, para ensinar conteúdos acadêmicos aos alunos no contexto de trabalho cooperativo para resolução de problemas». (Bender, 2014:15)

Atualmente, tornou-se objeto de grande interesse tendo em vista os resultados de aprendizagem obtidos por meio de sua aplicação. Ela aumenta consideravelmente a motivação do discente (primordialmente a motivação intrínseca) para apreender e trabalhar em equipe, sendo um dos principais motivos desta diferente atitude dos alunos o fato dos projetos se basearem em problemas do mundo real. 
Ensina William N. Bender: «Esse foco nas experiências de aprendizagem autênticas, em tarefas que os estudantes podem ser solicitados a realizar no mundo real, é uma característica de praticamente todas as experiências de ABP e, em geral, aumenta a motivação dos alunos para participarem dos projetos.» (Bender, 2014:17)

Este método de ensino ativo permite que sejam desenvolvidas habilidades importantes para o mercado de trabalho do século XXI que não são alcançadas satisfatoriamente com o ensino tradicional. Empregadores do século XXI estão procurando graduados que possuem habilidades sociais, já elencadas na introdução do presente trabalho, que podem ser desenvolvidas em nossos alunos por metodologias de ensino ativa como o Project Based Learning.

Tal metodologia está associada à ideia de que o conhecimento não é absoluto, e sim construído pelo estudante por meio de seu conhecimento pregresso e sua percepção global, dimensionando a necessidade de aprofundar, ampliar e integrar o conhecimento. (Brandao, 1998)

Os professores, durante a sua aplicação, devem assumir um novo papel, atuando não mais como o centro do conhecimento, como ocorre no ensino tradicional, mas como tutores, como verdadedeiros facilitadores da busca do conhecimento dos estudantes.

O discente também adota um papel diferente, torna-se responsável pela produção de seu próprio conhecimento, ele passa a ser ativo na busca do seu saber. Assim, mostra-se mais compromisado, independente e livre no que se refere ao processo de aprendizagem.

As metodologias participativas possibilitam a atuação efetiva dos envolvidos no processo educativo não os considerando como meros receptores. Nessa abordagem participativa, valorizam-se os conhecimentos e experiências dos participantes, envolvendo-os na discussão, identificação e busca de soluções para problemas emergentes. (NOBRE, et al. 2006:259).

O processo educativo nos leva ao compromisso de aprender, compreendendo a possibilidade de construção coletiva do conhecimento e de habilidades profissionais, por meio de outras maneiras de aquisição de conhecimento que não aqueles por nos tradicionalmente conhecidas, dando ao discente liberdade de escolha, voz em seu processo de aprendizagem e pela relação, agora diferente, entre professor e aluno, em outras palavras, entre o facilitador e o aprendiz.

A aprendizagem baseada em projeto organiza a aprendizagem em torno dos projetos, que se fundamentam em questões ou problemas desafiadores, envolvendo o aluno no entendimento do problema e em sua solução, na tomada de decisão ou atividades de investigação, oferecendo-lhe a chance de trabalhar autonomamente em períodos de tempo prolongados, o que resulta em apresentações ou produtos realísticos.

Outro entrave quando de discute a aplicação de metodologias ativas é a resistência 
dos docentes as mudanças. Alguns professores se mostram pressionados a cumprir o conteúdo que foi definido no incio do semestre. Não são poucos que resistem a aplicar metodologias inovadoras sob o fundamento de que se aplicar algo diferente das aulas expositivas não terá tempo hábil para esgotar o conteúdo programado. Esse é um obstáculo bastante relevante quando falamos de mudança de metodologias de aprendizagem.

O que deve se ter muito claro é que a abrangência do conteúdo não equivale, automaticamente, a aprendizagem seja qual for o formato de ensino.(Bender, 2014:131) Em uma aula expositiva, por exemplo, o professor «despeja» todo o conteúdo planejado, mas isso não significa que todos os discentes aprenderam. Com toda a certeza, várioas estudantes ficaram para trás no domínio daquele conteúdo ministrado.

Portanto, segundo William N. Bender (2014:132), dois pontos devem ser considerados: Mesmo aplicando uma metodologia inovadora como o Project Based Learning, o docênte consegue abranger todo o conteúdo, basta que haja planejamento, assim como se faz com metodologias tradicionais. O segundo ponto é que o rendimento com o ensino baseado em projetos é muito superior do que aqueles obtidos por métodos não ativos. O maior envolvimento do aluno em seu processo de aprendizagem faz com que seu rendimento seja bem mais elevado compardo a metodos de ensino clássicos.

Por sua vez, a metodologia ativa nomeada de Team Based Learning (TBL), consiste na utilização de uma estratégia instrucional que instiga o aluno a desenvolver, processar e maximizar a discussão intelectual e a dinâmica de equipe, deste modo, sua fundamentação teórica é fundada no construtivismo e na resolução de problemas. (Dias, 2016)

\section{O projeto}

A busca pela implantação das metodologias ativas de aprendizagem na Instituição de Ensino Superior Centro Universitário Antônio Eufrásio de Toledo foi o grande fomento ao projeto, de modo que a iniciativa contou suporte das mais variadas espécies para a realização do mesmo, o que incluiu a capacitação dos professores do curso de direito para introdução e avaliação de metodologias inovadoras.

Centro Universitário Antônio Eufrásio de Toledo de Presidente Prudente / SP - Brasil, ao qual somos ligados, é consorciado e membro do Comitê gestor de um consórcio de IES brasileiras denominado STHEM BRASIL/ LASPAU ao A LASPAU, filiada à Harvard. Trata-se de um programa Acadêmico e Profissional para as Américas, afiliado com Universidade de Harvard, que se dedica à missão de fortalecer o ensino superior no Hemisfério Ocidental desde sua fundação em 1964. Mais de 20.000 estudantes, pesquisadores, alunos e estudiosos e profissionais das Américas têm participado em programas desenhados ou administrados por LASPAU. (STHEM) 
Assim, professores são regularmente capacitados, incentivados e auxiliados na aplicação de metodologias de aprendizagem, como ocorreu no caso que passaremos a discorrer.

Tradicionalmente, a Instituição de Ensino Superior é representada por dois alunos e um coach em uma Competição Jurídica de Julgamento Simulado da Corte Interamericana de Direitos Humanos, realizada por meio de uma parceria entre a Washington College of Law, núcleo jurídico da American University, e a Comissão Interamericana de Direitos Humanos, sediada em Washington DC/USA, ${ }^{1}$ cujo objetivo principal é a promoção dos Direitos Humanos e preparação dos alunos de direito para atuarem junto ao Sistema Interamericano de Direitos Humanos (doravante SIDH).

Visando o aperfeiçoamento das equipes que representarão a Instituição de Ensino Superior, criou-se um grupo de estudos preparatórios para referida competição, cujo objeto de estudo constante do plano de ensino é o funcionamento, processamento e julgamento perante o SIDH, com foco na preparação dos alunos para participarem da referida competição. Os dois pontos mais relevantes e que são critérios de seleção das melhores equipes é o conhecimento do sistema interamericano de direitos humanos, seu funcionamento e jurisprudência, bem como a capacidade argumentativa.

Tendo sido elaborado um caso hipotético previamente, a competição se desenvolve em quatro etapas, sendo elas: (I) envio de memoriais escritos, na qual as equipes deverão enviar um conteúdo escrito, de caráter classificatório; (II) rodadas preliminares, de caráter eliminatório, na qual todas as equipes simulam um julgamento da Corte Interamericana de Direitos Humanos sobre o caso hipotético; (III) semifinais, na qual apenas participam as equipes classificadas entre as $20 \%$ (vinte por cento) melhores; e (IV) rodadas finais, na qual apenas as duas melhores equipes se enfrentam.

As rodadas orais desenvolvem-se em 45 (quarenta e cinco) minutos para cada equipe, na qual os alunos são sabatinados a todo o tempo pelos avaliadores.

Apenas uma vez na história da Instituição de Ensino Superior que uma equipe chegou à semifinal, isto no ano de 2012, de modo que os resultados se mantiveram nos mesmos patamares nos anos de 2013 em diante. Motivo pelo qual as metodologias ativas se mostraram necessárias para o desenvolvimento da capacidade argumentativa dos alunos em conjunto com os demais critérios de avaliação, na medida em que 2/3 (dois terços) da nota é composta exclusivamente pelo conteúdo das apresentações orais. Eis, então, nosso problema a ser resolvido.

A ideia inicial foi utilizar um projeto que trabalhasse com três premissas que não poderiam ser rejeitadas em momento algum: I) os alunos participantes seriam, em sua maioria esmagadora, de primeiro ano e que, portanto, não possuem domínio da prática jurídica; II) a questão motriz deveria ser algo envolvendo o Sistema Interamericano de Direitos Humanos, já que o objetivo central é a preparação para a

1. https://www.wcl.american.edu/hracademy/mcourt/index.pt.cfm 
competição internacional já mencionada; e III) em determinado momento, os alunos deveriam apresentar sustentações orais com o objetivo de convencer outros de seu ponto de vista.

Isto posto, surgiu a ideia de um julgamento de um caso hipotético que simulasse o plenário do Supremo Tribunal Federal, colocando os alunos como ministros e os professores como advogados. Os alunos enquanto juízes deveriam decidir sobre uma questão atual e polêmica de modo que seu posicionamento seria colocado em cheque pelos demais. A função dos professores, enquanto advogados, seria fazer as sustentações orais e, deste modo, balizar os alunos para que a questão central do caso fosse mantida.

O caso hipotético foi criado com base em um caso real recentemente julgado pelo STF no qual se avençou a possibilidade de indenização de presos que comprovadamente vivessem em situação degradante, humilhante e vexatória dentro dos presídios. E a temática foi escolhida em momento oportuno, na medida em que o país passa por uma crise carcerária em níveis históricos. Resumidamente, a questão motriz foi:

José Antônio dos Santos encontra-se encarcerado no presídio Xilindró, no qual a superpopulação atinge o triplo da capacidade, a alimentação se limita a uma refeição diária com produtos vencidos ou estragados, condições sanitárias inexistentes e poucos funcionários capazes de manter a segurança interna. Assim sendo:

- O Estado deve indenizar José Antonio dos Santos pela situação carcerária em que se encontra?

- Como se dará esta indenização? Em pecúnia ou em remissão da pena?

- Este julgado se estenderá a todos que se encontrem na mesma situação?

Em um primeiro momento, seguindo a etapa de pré-planejamento proposta pela própria sistemática do método, o projeto foi delineado de modo a separar os alunos em 11 (onze) grupos e, em cada grupo, um aluno seria escolhido para apresentar um voto de forma oral que representasse a posição do grupo ao qual pertence.

Para a construção da posição do grupo, seriam necessários 02 (dois) dias de preparação anterior, no qual os alunos tomariam ciência do projeto, iniciariam a preparação para realização da atividade com auxílio de materiais de apoio - tais como textos, julgados reais, vídeos de julgamentos do STF -, e, então, construiriam um voto escrito que representasse a opinião dos demais colegas do grupo.

O pré-planejamento previa expressamente a consulta e busca de auxílio de professores mais experientes e que já desenvolveram metodologias ativas anteriormente, pois a vivência de acertos e erros seria preponderantes na realização do projeto. E tal etapa foi fundamental, na medida em que uma problemática apresentada foi: se os alunos devem representar ministros que tentarão convencer os demais, todos eles já estarão com opinião formada individualmente e não convencerão os demais. 
Deste modo, em um consenso, chegou-se à conclusão de que seriam formados o7 (sete) grupos, obtendo-se assim, o7 (sete) ministros-alunos. De outro lado, o3 (três) professores convidados, e que não fizeram parte de nenhuma etapa anterior do projeto, atuariam como ministros-professores. Consequentemente, os ministrosalunos deveriam convencer os ministros-professores de seu ponto de vista por meio da sustentação oral.

Outro ponto relevante que sofreu alteração foi de que os alunos não poderiam escolher seu representante, o mesmo seria sorteado apenas no dia da sustentação oral. Isto para que todos os alunos se preparassem de maneira igual para a realização de tal tarefa. As demais etapas forma mantidas.

No primeiro dia de atividades, os alunos se separaram em grupos escolhidos pelos mesmos, e tiveram conhecimento do caso hipotético. Neste dia, também foi disponibilizado um caso real julgado pela Corte Interamericana de Direitos Humanos cuja decisão deveria ser resumida para que os alunos tivessem conhecimento sobre os parâmetros internacionais de julgamento.

Uma semana depois, no segundo dia de atividades preparatórias, com base no material disponibilizado anteriormente para pesquisa (dentre eles sites de busca de jurisprudência, doutrina sobre o tema, entre outros aparatos legais e técnicos), os alunos desenvolveram um voto escrito que representasse a opinião dos colegas. Registre-se que apenas em 02 (dois), dos 07 (sete) grupos, a conclusão foi unânime. Lembramos aos alunos que a decisão a qual chegassem, independente de qual fosse, deveria ser pautada na jurisprudência da Corte Interamericana de Direitos Humanos e sua

Foram convidados três professores de representação diversa para o dia do julgamento, um pertencente à cadeira de Filosofia Geral e do Direito, o segundo pertencente à cadeira de Direito Processual Penal e o terceiro pertencente à cadeira de Direito Processual Civil. O evento foi aberto ao público em geral e, aos alunos da graduação, valeria como horas de atividades complementares como forma de fomento à participação em atividades do gênero.

Minutos antes da realização do julgamento, foram sorteados os ministros-alunos e o ponto positivo do sorteio foi que os demais alunos não sorteados gostariam de fazer a apresentação oral, já que tinham se preparado para tanto, evidenciando a quebra daquela barreira do receio de falar em público e, principalmente, ter de debater com os demais colegas.

Iniciado o julgamento, dois professores fizeram papel de advogados fazendo sustentações orais. E este procedimento foi relevante na medida em que a partir das sustentações orais dos professores, os alunos teriam uma visão do objeto principal da discussão.

Após as sustentações orais dos professores, os ministros-alunos apresentaram votos orais um a um, e este momento foi muito interessante haja vista que os demais ministros (alunos ou professores) poderiam fazer interrupções instigando o debate 
e colocando em cheque a posição dos colegas. Um dos alunos defendeu com veemência sua posição mesmo quando confrontado por um dos professores, sempre mantendo a cordialidade e a formalidade exigida para o evento.

$\mathrm{O}$ dia do julgamento simulado tomou cerca de 04 (quatro) horas de trabalhos e todos os 21 (vinte e um) alunos participantes da estavam presentes. Um dos ministros-professores, que foi convidado a presidir a audiência, teve muita dificuldade de proferir o julgamento final, isto porque cada um dos ministros-alunos chegou a uma conclusão completamente diferente da outra, expondo a complexidade do tema.

Um aspecto negativo se apresentou durante a exposição do trabalho de um dos alunos. Devido a um problema técnico no aparelho eletrônico utilizado para armazenar o voto escrito, uma ministra-aluna não pôde iniciar sua apresentação em tempo. Porém, outra ministra-aluna percebeu o problema da colega e, de forma natural e espontânea, pediu a palavra para apesentar sua sustentação oral enquanto o imprevisto fosse solucionado. Em seguida, o defeito foi contornado e o aparelho voltou a funcionar corretamente, possibilitando a apresentação da aluna.

Ao final, todos os participantes, inclusive os que não foram sorteados, manifestaram sua total satisfação pela participação no evento, principalmente pela possibilidade de se aprofundar sobre o tema e conhecer várias posições divergentes dialogando com todas as diversas formas de solução do problema proposto.

\section{Conclusão}

Concluímos que a atividade relatada que fez uso da metodologia do Project Based learnig cumulada com a metodologia do Team Based Learning representa um caso de sucesso do ensino-aprendizagem com metodologia ativa. Ela propiciou o desenvolvimento de um produto, qual seja, o parecer sobre o caso, além de proporcionar aos alunos dividirem os resultados obtidos com outros discentes e docentes da Instituição de ensino, bem como de tomar conhecimento de pontos de vistas diferentes sobre o tema. Eles foram além da teoria, aplicando seus conhecimentos teóricos a um problema real experimentado e rotineiro em nosso país, além de desenvolverem sua capacidade de oratória.

Eles puderam relacionar os conteúdos teóricos e práticos em um produto final, sendo que durante a realização do projeto, eles enfrentaram problemas do cotidiano profissional e se envolveram nas decisões concernentes a sua própria aprendizagem, tornando-se sujeitos ativos e os principais responsáveis pelo processo da busca do conhecimento.

As habilidades específicas que pretendíamos desenvolver nos discentes por meio da realização desse projeto (pensamento crítico, a habilidade para solução de problemas da vida real, capacidade de trabalho em equipe e oratória) foram atingidos indo além das expectativas. 


\section{Referências}

Bender, William (2014). Aprendizagem Baseada em Projetos: educação diferenciada para o século XXI. Tradução Fernando de Siqueira Rodrigues. Revisão técnica: Maria da Graça Souza Horna. Porto Alegre: Penso.

Berbel, Neusi Aparecida Navas (2011) As metodologias ativas e a promoção da autonomia de estudantes. Seminário de Ciências Sociais e Humanas, Londrina, 32 (1): 25-40. jan./jun. 2011. Disponível em: http://www.uel.br/revistas/uel/index.php/seminasoc/article/view/10326/10999. Acesso em: 10 de março de 2017, p. 29.

Brandẽo, Carlo Rodrigues; Lessadrini, Cristina Dias; LIMA, Edvaldo Pereira (1998). Criatividade e novas metodologias. 2. ed. São Paulo: Fundação Petrópolis, (4).

Ching, Ruth Cristina Hernández (2018). «El modelo pedagógico a través del aprendizaje basado en problemas en un curso de investigación bibliográfica.» Revista Electrónica Educare 22(2):1-22.

DiAs, Ricardo Freitas (2015). «Team-based learning: fazendo os alunos pensarem «fora da caixa», os elementos essenciais para sua implantação» Rebes Revista Brasileira de Educação e Saúde ISSN - 2358-2391. Disponível em: <http://www.gvaa.com.br/ revista/index.php/REBES/article/view/2676/2828>. Acesso em: 01/10/ 2016.

Fernández, Carina Lorena, and María Inés Aguado (2017). «Aprendizaje basado en problemas como complemento de la enseñanza tradicional en Fisicoquímica.» Educación Química 28 (3): 154-162.

Melo, Carmen Cecilia, Espinoza, and Iván Sánchez Soto (2017). «Eficacia de un Recorrido de Estudio e Investigación en el desarrollo de estrategia de aprendizaje y tipo de aprendizaje.» Espacios 38 (60)

Nobre, João Carlos Silva; Loubach, Denis Silva; Cunha, Adilson Marques da; Dias Luiz Alberto Vieira (2006). < Aprendizagem Baseada em Projeto (Project-BasedLearning - PBL) aplicada a software embarcado e de tempo real $>$. Apresentado no XVIII Simpósio Brasileiro de informática na educação - SBIE - UNB/ UCB:258 a 267. Disponível em: http://www.Br-ie.Org/pub/index.Php/sbie/article/view/486. Acesso em: 01/10/2016.

Paiva, Kely César Martins de, Lage, Fernando Procópio, Santos, Sthefania Navarro dos, \& Silva, Carla Ribeiro Volpini. (2011). «Competências profissionais e interdisciplinaridade no Direito: percepções de discentes de uma faculdade particular mineira» Educação e Pesquisa, 37(2):355-373.

Reyes García, Fredy, Luis José Vera Guadrón, and Elio Rafael Colina Caldera (2014). «Creative Strategies to Promote Meaningful Learning in Simulated Practice Teaching.» Opcion 30, 75: 55-74.

Rodríguez, Arturo; Leonardo Ramírez, and Washington Fernández (2017). «Active Methodologies to Achieve Comprehension.» Formación Universitaria 10(1): 79-88. 
Rodríguez-CASAdo, Maria Rocio, and Teresa Rebolledo-Gámez (2017). «Evaluación de metodologías participativas: una experiencia en el ámbito universitario» Revista de Humanidades 31: 99-122.

Rodríguez-Santero, Javier; Juan Jesús Torres-Gordillo, and Víctor Hugo PereraRodríguez (2016). «Contributions of the Pbl Method in Achieving Professional Action Competences.» Bordon. Revista de Pedagogía 68 (4): 155-77.

Santos, David Moises B.; Saba, Hugo; Rocha Junior, João; Sarinho, Victor (2007). $<$ Aplicando Project-Based Learning no Estudo Integrado de Engenharia de Software, Análise e Projeto de Sistemas e Banco de Dados>. XXXV Congresso Brasileiro de Educação em Engenharia - COBENGE. Disponível em: :http://www. abenge.org.br/CobengeAnteriores/2007/artigos/441- Hugo\%20Saba\%2oPereira\%20Cardoso.pdf. Acesso em: 01/10/2016.

STHEM/Brasil. Consorcio de IES Brasileiras e Laspau. Disponível em: HTTP://STHEMBRASIL.COM/SITE/O-CONSORCIO/. ACESSO EM: O1/10/2016.

STOLK, Jonathan (2016) >Slides Preparados Por Jonathan Stolk>. Disponível: http:// www.labmi.com.br/wp-content/uploads/2014/05/Apresenta\% $\mathrm{C}_{3} \% \mathrm{~A}_{7} \% \mathrm{C}_{3} \% \mathrm{~A}_{3}$ motiva\% $\mathrm{C}_{3} \% \mathrm{~A} 7 \% \mathrm{C}_{3} \% \mathrm{~A}_{30}-\mathrm{UNISAL}-\mathrm{Brazil-MAIO} 2014-$ reduced.pdf. Acesso em: 01/10/2016.

Viera, Oscar Vilhena (2012). > Desafios Do ensino jurídico num mundo em transição: o Projeto da direito GV. IN: Ensino do direito para um mundo em transformação > / organizadores Marina Feferbaum, José Garcez Ghirardi . São Paulo: Fundação Getulio Vargas. (Coleção acadêmica livre. Série didáticos).

\section{Sobre os autores}

Fernanda de Matos Lima Madrid é Mestre em Ciências Jurídicas pela Universidade Estadual do Norte do Paraná - UENP. Especialista em Direito Penal e Processo Penal pela Universidade Estadual de Londrina. Graduada em Direito pelas Faculdades Integradas «Antonio Eufrásio de Toledo» de Presidente Prudente. Professora de Direito Penal do Centro Universitário «Antonio Eufrásio de Toledo» de Presidente Prudente. Integrante do Laboratório de apoio pedagógico em inovação acadêmica do Centro Universitário "Antônio Eufrásio de Toledo». Advogada criminalista. fm.com@ ig.com.br

Lucas Octávio Noya dos Santos é Mestrando em Ciências Jurídicas pela Universidade Estadual do Norte do Paraná - UENP. Graduado pelo Centro Universitário Antonio Eufrásio de Toledo de Presidente Prudente. Estagiário docente pelo Centro Universitário do Centro Universitário Antonio Eufrásio de Toledo de Presidente Prudente. Advogado. Fm.com@ig.com.br 